\title{
ERRATUM
}

\section{A basic dynamic transmission model of Staphylococcus aureus in the US population - ERRATUM}

\section{HOGEA, T. VAN EFFELTERRE ANd C. J. ACOSTA}

doi: http://dx.doi.org/10.1017/S0950268813001106. Published online: 23 May 2013

In the above-mentioned article [1] the y axis in Figure $3 a$ is incorrect. The correct version is given below.

US pop. growth (estimated) $\left(\times 10^{8}\right)$

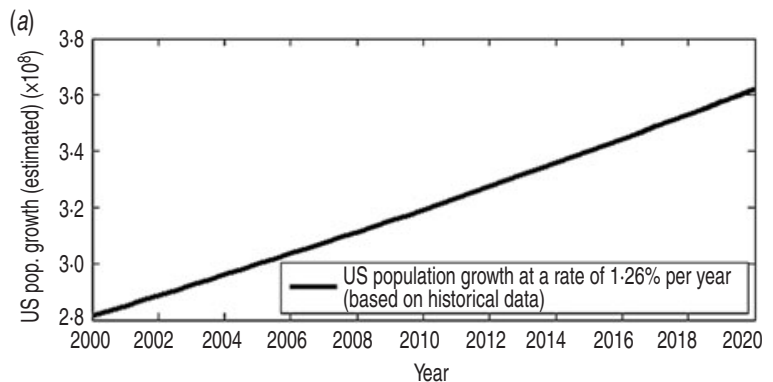

Fig. 3. Baseline model projections: potential MRSA infection incidence increase and gradual replacement of MSSA over the next decade in the USA in the absence of systematic infection control, based on the 1999-2005 national trends (infection and colonization) and assuming strong competition between MRSA and MSSA for colonization of susceptible hosts [19]. (a) Projection of US population growth for period 2000-2020, based on historical US Census data.

\section{REFERENCE}

1. Hogea C, Van Effelterre T, Acosta CJ (2014). A basic dynamic transmission model of Staphylococcus aureus in the US population. Epidemiology and Infection 142: 468-478. doi:10.1017/S0950268813001106. Published online: 23 May 2013. 